\title{
A Criança com Deficiência Institucionalizada e o Ensino de Habilidades Básicas: Um Estudo de Caso
}

\author{
Iasmin Zanchi Boueri \\ Universidade Federal de São Carlos \\ Andréia Schmidt \\ Universidade de São Paulo
}

\begin{abstract}
RESUMO
Este trabalho teve como objetivo verificar as mudanças ocorridas no repertório de uma criança com deficiência, institucionalizada e em condição de abandono, ao passar por um procedimento focado no ensino de habilidades básicas. Participou da pesquisa uma menina de sete anos, com severo atraso no desenvolvimento, moradora de uma instituição residencial para pessoas com deficiência. Foi realizada uma avaliação inicial do repertório da criança (linha de base) por meio da aplicação de um protocolo de habilidades básicas, que possibilitou determinar as condutas que seriam ensinadas durante o desenvolvimento do programa de aquisição de habilidades básicas. Para verificar as mudanças no repertório comportamental da participante foram aplicadas avaliações quinzenais. Os resultados foram acompanhados por meio de um delineamento de linha de base múltipla entre comportamentos. Observou-se, a partir das avaliações quinzenais, que houve aumento na frequência dos comportamentos ensinados após início da implementação do programa de ensino. Tal aumento não foi observado nas demais habilidades podendo-se, portanto, afirmar que a modificação provavelmente foi devida à intervenção realizada. Pode-se concluir que a participante aprendeu as habilidades ensinadas ao passar pelo procedimento de ensino em questão, mesmo residindo em um ambiente institucional desfavorável para aprendizagem de novos comportamentos.
\end{abstract}

Palavras-chave: procedimento de ensino; habilidades básicas; deficiência; crianças institucionalizadas.

\begin{abstract}
The Institutionalized Child with Disabilities and the Teaching of Basic Skills: a Case Study

This case study was designed to verify changes on the behavioral repertoire occurred with a child with disability, abandoned and institutionalized, after undergoing a procedure focused on the teaching of new basic skills. The participant was a seven-year-old girl with severe developmental delay, who was living in an institution that houses people with disabilities. First, an evaluation of the initial repertoire of the child was done (baseline), by applying a protocol of basic skills, which allowed researchers to determine which conducts would be taught during the program for acquisition of basic skills. In order to verify any changes in the participant's behavioral repertoire, evaluations were made every two weeks. The follow up of the results was done by a multiple baseline design across behaviors. The biweekly evaluations showed an increase on the frequency of the behaviors been taught through implementation of the teaching program. The increase was not observed on other behaviors, which indicates that the changes were probably a result of the intervention applied. The results showed that the participant was able to learn new basic skills, even though residing in an institutional environment which wasn't favorable for the learning of new behaviors.
\end{abstract}

Keywords: teaching procedures; basic skills; disabilities; institutionalized children.

Um estudo realizado pelo IBGE em 2006 junto a entidades de assistência social sem fins lucrativos revelou que, no Brasil, há 677 instituições que se definem como "abrigos" (IBGE, 2007). Entende-se como instituição de abrigo aquela onde há o acolhimento de pessoas que se encontram em situação de vulnera- bilidade, risco pessoal e/ou social, em caráter especial e provisório, em pequenos grupos, com o objetivo de restabelecer e reconstituir vínculos e autonomia (IBGE, 2007; Paula, 2008). No caso de crianças e adolescentes, trata-se de uma medida de proteção provisória e excepcional, que é utilizada como forma 
de transição para colocação em família substituta, não implicando privação de liberdade. Essas instituições podem acolher crianças, jovens, adultos e idosos, com ou sem deficiência (IBGE, 2007). Considerando a importância dos serviços prestados por essas instituições, é necessário que se façam estudos sobre seu funcionamento e a qualidade dos serviços oferecidos à população atendida.

Dentre os estudos realizados no país junto a abrigos, muitos focalizam a situação de crianças e jovens que vivem nessas instituições residenciais. A pesquisa de Salina (2007), por exemplo, investigou as estratégias utilizadas por conselheiros tutelares envolvidos na avaliação de abrigos. A autora realizou um levantamento junto a esses profissionais para verificar quais indicadores de qualidade controlavam o seu comportamento de avaliar, considerando que estas instituições passam constantemente pela apreciação destes profissionais e se apresentam, em geral, como ambientes desfavoráveis ao desenvolvimento do potencial de seus residentes. $\mathrm{O}$ estudo verificou que os participantes, ao relatarem os critérios que empregavam para avaliar as instituições, citavam com baixa frequência aspectos relacionados às práticas educativas dos monitores dos abrigos e cuidados da entidade para manutenção dos vínculos familiares, aspectos estes considerados importantes para o desenvolvimento dos moradores das instituições. Outra pesquisa, desenvolvida por Prada (2007), avaliou os tipos de práticas educativas empregadas por educadores de uma instituição residencial e relatou os efeitos de uma capacitação para esses educadores sobre o seu manejo diário com as crianças abrigadas. Ao avaliar as práticas educativas empregadas pelos educadores, foram constatados altos escores de uso de monitoria relaxada e monitoria negativa no pré-teste, escores que diminuíram significativamente após a capacitação (pós-teste). Também no pós-teste, observou-se um aumento significativo dos escores de emprego de monitoria positiva em comparação com o pré-teste. Os dados apontaram que procedimentos com os monitores podem trazer benefícios para os residentes, mas também indicam a necessidade de outras pesquisas nesse sentido, em ambientes similares. Ambas as pesquisas aqui relatadas buscavam descrever aspectos importantes relacionados aos ambientes de institucionalização (como seu funcionamento e avaliação) e investigar procedimentos que possibilitassem que aqueles ambientes se tornassem mais favoráveis ao aprendizado dos residentes.

Apesar de os abrigos serem alvos de muitos estudos (Carvalho, 2006; Costa 2005; Orionte, 2004; Prada,
2007; Salina, 2007), verifica-se uma escassez de pesquisas desenvolvidas em instituições residenciais destinadas ao cuidado de crianças e adolescentes com deficiência. Um trabalho com esse enfoque é o de Grossi (1996), que teve como objetivo capacitar duas atendentes para ensinarem uma criança a realizar diferentes tarefas ao longo de sua rotina diária. As duas atendentes realizavam o manejo diário de uma criança que tinha diagnóstico de deficiência intelectual e residia na instituição de abrigo na qual foi desenvolvida a pesquisa. Foi realizado um levantamento da rotina da criança e uma avaliação inicial de seu repertório. Posteriormente, foi proposta uma mudança nas atividades diárias e implementado um programa para capacitar as atendentes a trabalhar com esta criança. A autora utilizou um delineamento de linha de base múltipla entre sujeitos (as atendentes) para o acompanhamento dos resultados. $\mathrm{O}$ estudo demonstrou que, a partir dessa capacitação, as atendentes passaram a lidar funcionalmente com a criança. Com a mudança do comportamento das atendentes, a criança, que inicialmente apresentava vários comportamentos autolesivos, apresentou a diminuição da frequência de tais condutas. $\mathrm{O}$ estudo demonstrou a necessidade de trabalhar junto a profissionais que realizam o cuidado diário de residentes desse tipo de instituição, mas também apontou algumas dificuldades enfrentadas nesse processo, como a falta de preparo desses profissionais e o pequeno número de pesquisas que descrevam procedimentos eficazes para o ensino de crianças e jovens inseridos neste contexto de institucionalização no Brasil.

Todos esses dados apontam para a relevância do desenvolvimento de pesquisas em instituições que abriguem crianças ou jovens com deficiência para que se possa realizar um levantamento mais geral das condições ambientais enfrentadas por esta população. Além disso, é importante investigar procedimentos de ensino a serem implementados nestes ambientes que proporcionem a pessoas com deficiência o desenvolvimento de seu potencial.

Windholz e Meyer (2000) afirmam que o atendimento a crianças com deficiência deve construir caminhos que visem prepará-las para sua inclusão social, permitindo maior autonomia e independência. Para isso, é necessário começar desde a infância a realizar trabalhos que propiciem o desenvolvimento das habilidades pertinentes para se alcançar tais objetivos. Muitos estudos realizados a partir da vertente da análise do comportamento mostraram-se promissores nesta direção. 
A análise do comportamento tem como objeto de estudo o comportamento do indivíduo (Micheleto, 1997), considerando comportamento como a interação do indivíduo com o seu ambiente físico e social; o que caracteriza o comportamento é a sua sensibilidade aos efeitos que produz no ambiente (Matos, 1997). A análise do comportamento parte da constatação de que há ordem e regularidade no comportamento (Todorov, 1982), ou seja, as consequências produzidas por um dado comportamento determinam a sua probabilidade de ocorrência em uma situação futura semelhante (Micheleto, 1997).

A análise aplicada do comportamento faz parte do campo de intervenção planejada do analista do comportamento, que pode ser conduzida em diversos contextos (Carvalho Neto, 2002). Caracteriza-se como uma prática científica desenvolvida a partir de quatro passos fundamentais: avaliação inicial do repertório de entrada do indivíduo (linha de base) e das contingências presentes no ambiente no qual ele está inserido; definição de objetivos a serem alcançados (as habilidades que o indivíduo será capaz de realizar ao final do procedimento); definição e aplicação do programa de ensino e dos procedimentos a serem utilizados; e avaliação do programa (observar a necessidade de mudança do programa no decorrer de seu desenvolvimento ou sua eficácia). Os procedimentos de ensino utilizados com crianças com deficiência, quando baseados na análise aplicada do comportamento, caracterizam-se pela constante mudança, experimentação e registros de respostas para acompanhamento (Braga-Kenyon, Kenyon \& Miguel, 2002).

Os procedimentos de ensino são conduzidos de maneira formal ou informal. $\mathrm{O}$ ensino informal faz com que o educador fique sob o controle dos comportamentos da criança, podendo ser empregado para iniciar uma relação com ela e como aquecimento para o início de uma sessão formal. Durante o ensino formal criam-se condições de controle máximo de estímulo, pelo arranjo de um ambiente no qual as possibilidades de distração são removidas ou reduzidas e a presença do material de estímulo é cuidadosamente selecionada e programada. $\mathrm{O}$ ambiente mais restrito auxilia na aprendizagem por permitir que a criança dirija sua atenção a um estímulo por vez, e também possibilita a repetição frequente das tarefas, sendo estas condições importantes para a aprendizagem de novos repertórios (Windholz \& Meyer, 2000).

Vários estudos mostram que situações formais de ensino podem propiciar a aprendizagem de diversos comportamentos para indivíduos que tenham severo atraso no desenvolvimento (Hersen \& Bellack, 1976; Spangler \& Marshall, 1983). O trabalho de Hersen e Bellack (1976) é um exemplo, e teve como objetivo verificar o efeito de um treinamento de habilidades sociais em um jovem de 19 anos com desordem mental crônica. Os autores demonstraram o aumento da ocorrência das habilidades ensinadas, aumento que se manteve após o término das intervenções.

Há indicativos na literatura, também, que indivíduos com defasagens severas no desenvolvimento possuem, geralmente, dificuldades no desenvolvimento de habilidades básicas referentes à sensopercepção, condições motoras gerais, compreensão e execução, habilidades que possibilitam às pessoas uma melhor relação com o mundo que as cerca. Para estes indivíduos, sejam eles bebês ou crianças maiores, é preciso uma programação planejada e dirigida, muitas vezes com procedimentos precisos e elaborados, que os auxilie no desenvolvimento destas habilidades (Windholz, 1988). Porém, os estudos empreendidos para testar procedimentos formais de ensino a indivíduos severamente prejudicados são realizados ou em ambientes educacionais planejados especificamente para tal (como por exemplo, Araujo \& Ferreira, 2008), ou são conduzidos em realidades culturais (e/ou ambientais) distintas das encontradas em instituições de abrigo no Brasil (como por exemplo, Santos, Almeida, \& Bzuneck, 1992; Silva, 1999). Desta forma, pouco se sabe se procedimentos formais de ensino podem ter resultados positivos quando realizados em ambientes institucionais destinados a pessoas com deficiência em nosso país.

Tendo em vista a importância apontada pela literatura da aprendizagem de habilidades iniciais e a necessidade do desenvolvimento de estudos nos ambientes institucionais destinados a pessoas com deficiência, esta pesquisa teve o objetivo de verificar os resultados obtidos por uma criança com deficiência, institucionalizada e em condição de abandono, quando exposta a um procedimento focado no ensino de habilidades básicas.

\section{MÉTODO}

\section{Participante}

Participou da pesquisa uma menina de sete anos, com severo atraso no desenvolvimento, que apresentava hemiplegia leve à direita (cadeirante) e ausência de linguagem verbal e não verbal. Uma avaliação neuropediátrica sugeriu como hipótese diagnóstica Síndrome de Rett ou Síndrome de Landau-Kleffner, 
porém, devido à ausência de dados da história clínica, não foi possível confirmação de nenhum destes diagnósticos. A participante residia em uma instituição de abrigo para pessoas com deficiência, onde deu entrada com três anos de idade. No prontuário da criança, disponibilizado pela instituição, havia registros de que ela foi encontrada em situação de abandono, em péssimas condições de higiene e com indícios de maus tratos, o que motivou o conselho tutelar a recolhê-la na instituição de abrigo.

A participante não saía da instituição, exceto para atendimentos médicos. Ela participava de algumas atividades recreativas desenvolvidas na escola especial da instituição no período da manhã, três a quatro vezes durante a semana, e tinha atendimento em fisioterapia, duas vezes por semana. Quando não estava na escola ou em atendimento, a criança permanecia junto com os outros moradores nos salões ou no pátio, na cadeira de rodas ou no berço. Não havia a programação de qualquer atividade específica para ensino de habilidades básicas na instituição. Mesmo nas interações diárias entre os auxiliares de enfermagem e os residentes, não havia qualquer objetivo educacional envolvido.

Observando a criança em seu ambiente natural pode-se constatar, nos momentos em que ela permanecia ociosa em seu berço ou cadeira de rodas, a presença de comportamentos estereotipados e autolesivos. Nas ocasiões em que havia contato físico entre a atendente e a criança, durante a troca, o banho e a alimentação, esta emitia comportamentos de evitação e afastamento.

\section{Local}

A pesquisa foi conduzida nas dependências de uma instituição de abrigo para pessoas com deficiência, abandonadas pelos pais e/ou recolhidas pelo conselho tutelar regional por motivo de maus tratos. A participante residia em uma ala desta instituição, que abrigava mais 30 pessoas com deficiência aproximadamente, divididas em três grupos: moradores que usavam sonda e que eram cadeirantes, com idade entre 5 e 37 anos; crianças cadeirantes e que não usavam sonda, com idade entre 2 e 12 anos; adoles- centes que não usavam sonda, cadeirantes e não cadeirantes, com idade entre 13 e 20 anos. Cada grupo de aproximadamente 10 moradores era atendido por duas auxiliares de enfermagem que deveriam realizar todas as atividades, como controlar a medicação dos residentes e realizar sua higiene e alimentação. Os moradores permaneciam em salões durante a maior parte do tempo em cadeiras de rodas, berços ou tatames. Exceto pela circulação das atendentes, visitantes e estagiários no local, ou pelos sons provenientes da fala ou do manuseio dos materiais para execução dos cuidados, nenhum outro evento acontecia regularmente no local.

As sessões de atendimento desta pesquisa ocorriam em locais escolhidos de acordo com a atividade que as auxiliares de enfermagem estavam realizando. Por exemplo, quando elas estavam alimentando as crianças, a participante era atendida no dormitório; quando estavam trocando as crianças, o atendimento ocorria no refeitório. $\mathrm{O}$ ambiente em que os atendimentos ocorriam era escolhido de acordo com os seguintes critérios: ser silencioso, não ter a presença de outros moradores da instituição e não atrapalhar as atividades que as auxiliares estavam realizando.

\section{Instrumentos}

Para a pesquisa foram utilizados três instrumentos desenvolvidos com base em um currículo para ensino de habilidades para crianças com deficiência (Winholz, 1988):

- um protocolo de avaliação de habilidades básicas, contendo as condutas encontradas no início do desenvolvimento infantil, como comportamentos referentes à percepção visual, auditiva, tátil, contato visual, comportamento exploratório, procura de objetos, imitação motora e atendimento de ordens;

- uma folha de registro para revisão quinzenal de condutas, elaborada a partir do resultado obtido com a aplicação do protocolo de avaliação de habilidades básicas, composta pelas condutas que apresentaram frequência inferior a $90 \%$ na linha de base. Essas condutas estão descritas na Tabela 1. 
TABELA 1

Apresentação das Habilidades Básicas Avaliadas na Revisão Quinzenal

\section{HABILIDADE}

DESCRIÇÃO

PERCEPÇÃO VISUAL

Perceber diferentes estímulos visuais

Manipular objetos que entrem no campo visual

PERCEPÇÃO AUDITIVA

Localizar fontes sonoras

Perceber sons de diferentes intensidades

PERCEPÇÃO TÁTIL

Explorar diferentes texturas

Identificar objetos a partir do contato físico

Explorar 0 ambiente com as mãos

CONTATO VISUAL OLHO A OLHO

PROCURAR OBJETOS
Reagir à mudança de luz (apagada ou acesa), observar dois objetos distintos realizando alternância de olhar entre eles, olhar para o rosto humano, observar figuras referentes a objetos conhecidos.

Qualquer manipulação intencional de objetos que sejam colocados em seu campo visual, podendo ser realizada com qualquer parte do corpo.

Olhar e emitir qualquer comportamento em direção ao som produzido.

Reagir às intensidades de sons que são produzidos no ambiente. Podendo demonstrar desagrado quando o ruído for alto, afastando com as mãos o objeto utilizado para emitir 0 som.

Reagir de diferentes formas a determinados materiais ao sentir sua textura, podendo mostrar preferência por alguns materiais e desagrado por outros. Como, por exemplo, retirar a mão rapidamente de superfícies ásperas ou continuar passando a mão em superfícies macias.

Manusear objetos e, após conhecer bem alguns objetos, ser capaz de encontrá-los sem olhar, a partir de um pedido.

Explorar e brincar com as mãos. Manusear diferentes objetos. Utilizar as mãos para executar tarefas simples, como por exemplo, alcançar algum objeto.

Manter contato olho a olho sempre que solicitado, por no mínimo 3 segundos, sem ajuda física e dentro de um período de 15 segundos após a solicitação.

Remover um anteparo que encobre um determinado objeto e pegar o mesmo, sempre que a posição do objeto e a colocação do anteparo tenham sido observadas pela criança, dentro de um período de até 15 segundos após a colocação do anteparo.

Reproduzir comportamentos observados da forma mais parecida possível ao modelo apresentado, dentro de um período de até 15 segundos, sempre que for solicitado.

Nota: Baseado em Windholz (1988).

- um programa de atendimento contendo a descrição detalhada de todas as atividades desenvolvidas durante a intervenção para ensino das habilidades "contato visual olho a olho", "procurar objetos" e "imitação motora"; além da descrição das sessões, havia modelos de folhas de registro utilizadas para anotação dos procedimentos de ajuda necessários para que a participante realizasse o comportamento solicitado, quando este estava sendo ensinado. Foram utilizados três tipos de procedimento de ajuda, descritos em Windholz (1988):

a) A ajuda física consistia no auxilio prestado à criança para que executasse o que era solicitado, podendo ser total $(100 \%)$, parcial $(75 \%$ ou $50 \%)$ ou mínima $(25 \%)$. Por exemplo, durante o ensino da habilidade "procurar objetos", ao solicitar para a criança que pegasse o objeto escondido atrás de uma toalha. Caso a criança não iniciasse o comportamento, a auxiliar lhe dava um prompt ( $25 \%$ de ajuda) encostando em seu cotovelo e empurrando-o em direção à toalha; caso a criança, a partir do prompt, não continuasse o comportamento, a auxiliar empurrava o antebraço da criança até que sua mão fosse embaixo da toalha (50\% de ajuda); caso a criança não finalizasse o comportamento sozinha a auxiliar então colocava sua mão sobre a mão da criança e fazia com que esta pegasse o objeto que estava embaixo da toalha (75\% de ajuda); se a criança não trouxesse o objeto para seu campo visual a auxiliar deveria fazê-lo (100\% de ajuda). 
b) A dica visual era um procedimento de auxílio, no qual se buscava facilitar o aparecimento da resposta correta pelo uso de recursos visuais. Por exemplo, durante o ensino da habilidade "contato visual" era utilizada uma garrafa de $220 \mathrm{ml}$ cheia de água com purpurinas e miçangas em seu interior, para captar o olhar da criança e conduzi-lo ao contato visual olho a olho com a pesquisadora.

c) A dica verbal consistia em dar instruções adicionais à criança para que executasse a habilidade que estava sendo ensinada. Por exemplo, durante o ensino da conduta "imitação motora", caso a criança não olhasse em direção à pesquisadora para realizar o movimento que estava sendo ensinado, ela deveria solicitar que a criança olhasse em sua direção e realizasse o movimento que estava sendo executado. Ao mesmo tempo em que a pesquisadora realizava o movimento, deveria descrever o que estava fazendo.

\section{Procedimento de coleta de dados}

Esta pesquisa foi aprovada pelo Comitê de Ética em Pesquisa da Universidade Positivo. Inicialmente, foi realizada uma descrição da rotina da participante com base no relato das atendentes da instituição que trabalhavam diretamente com ela. Em seguida, foi feita a avaliação da criança, utilizando o protocolo de avaliação de habilidades básicas.

O protocolo de avaliação foi aplicado em três dias alternados. Cada conduta era solicitada três vezes e a presença ou ausência de resposta era registrada. $\mathrm{O}$ protocolo foi empregado como linha de base e como ponto de partida para a elaboração do instrumento de revisão quinzenal (na revisão eram avaliados apenas os comportamentos com frequência menor que $90 \%$ na linha de base, o que incluía os comportamentos ensinados). Os comportamentos escolhidos para serem ensinados foram contato visual, procurar objetos e imitação motora, pois estavam ausentes no repertório da participante (de acordo com a avaliação inicial) e eram as habilidades necessárias para que ela desenvolvesse atividades mais complexas.

O programa era composto por "situações de ensino", nas quais as pesquisadoras criavam condições favoráveis às aprendizagens da criança. Foram realizados atendimentos três vezes por semana, em dias alternados, e cada sessão tinha duração de aproximadamente 1 hora e 30 minutos. Neste trabalho serão descritos os dados referentes ao período inicial de quatro meses de intervenção (52 sessões).
Em cada sessão eram realizadas duas situações de ensino, com um intervalo recreativo entre elas. Inicialmente, era realizado um contato com a criança, no qual eram cantadas diversas músicas e eram descritas as atividades que seriam desenvolvidas. Em um segundo momento era iniciada a primeira situação de ensino, que durava aproximadamente 30 minutos; após a situação de ensino, era realizada uma atividade recreativa e, em seguida, era conduzida a segunda situação de ensino, com a mesma duração da primeira. Para finalizar, eram realizadas atividades que promovessem o relaxamento. Durante a situação de ensino, cada habilidade era solicitada dez vezes. Após um período de 10 segundos de espera para emissão da resposta, caso a participante não emitisse o comportamento solicitado ou o fizesse apenas parcialmente, eram realizados procedimentos de ajuda para que ela concluísse a atividade (dicas visuais, físicas ou verbais). No decorrer das intervenções, o procedimento de ajuda foi sendo retirado para que a participante realizasse os comportamentos de forma independente.

Ao longo do programa era aplicada, quinzenalmente, uma revisão de habilidades (avaliação). Durante a revisão quinzenal os comportamentos eram solicitados três vezes e não eram oferecidos procedimentos de ajuda.

\section{Procedimento de análise de dados}

Os dados obtidos a partir da aplicação do protocolo de avaliação de habilidades básicas e das revisões quinzenais foram analisados quantitativamente, utilizando um delineamento de linha de base múltipla entre comportamento, pois vários comportamentos diferentes de uma única participante foram registrados em diferentes momentos da intervenção (Cozby, 2003).

\section{RESULTADOS}

A partir do início das sessões de intervenção, quinzenalmente foram realizadas avaliações, tanto das habilidades efetivamente ensinadas, quanto das demais condutas que estavam ausentes do repertório da participante, ou que apresentaram porcentagem de emissão correta inferior a $90 \%$ na linha de base. A Figura 1 apresenta os dados das avaliações das condutas que não foram alvo de intervenção e a Figura 2, os das habilidades que foram especificamente ensinadas. 
Localizar fontes sonoras

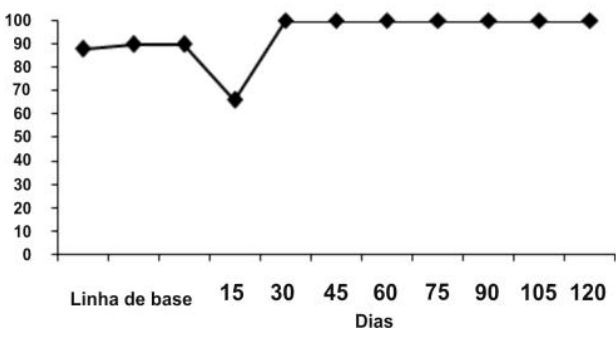

Manipular objetos que entrem

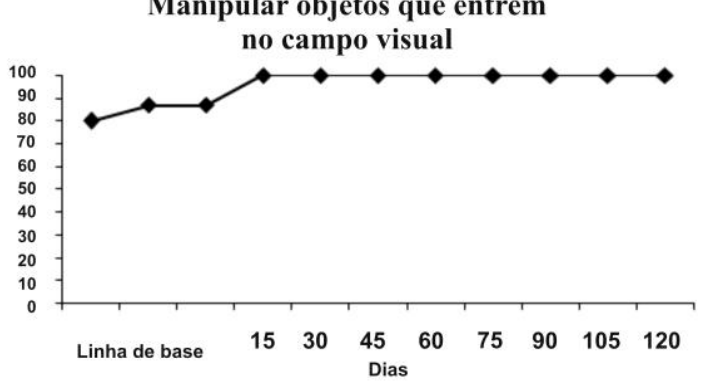

Perceber sons de diferentes intensidades

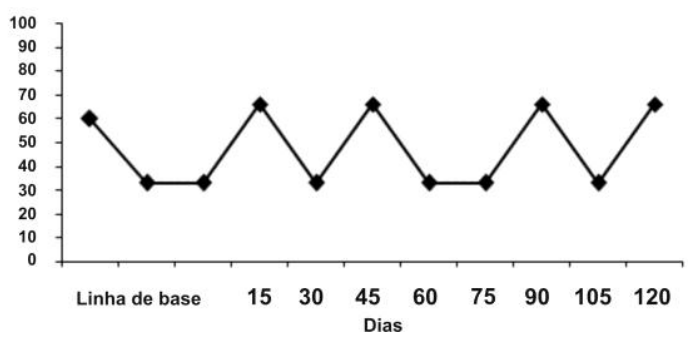

Identificar objetos por meio do contato físico

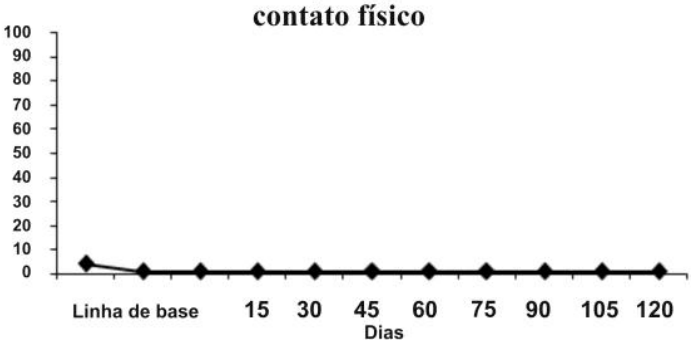

Explorar o ambiente com as mãos

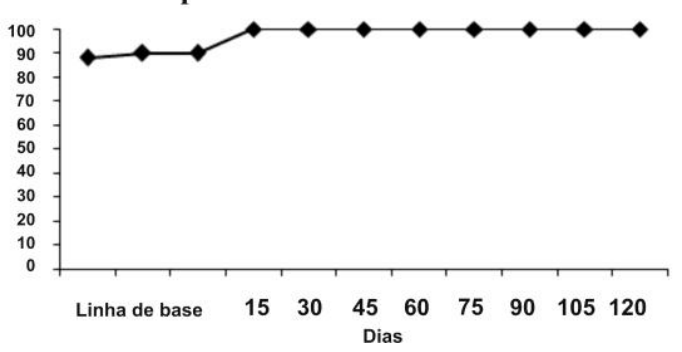

Explorar diferentes texturas



Perceber diferentes estímulos visuais

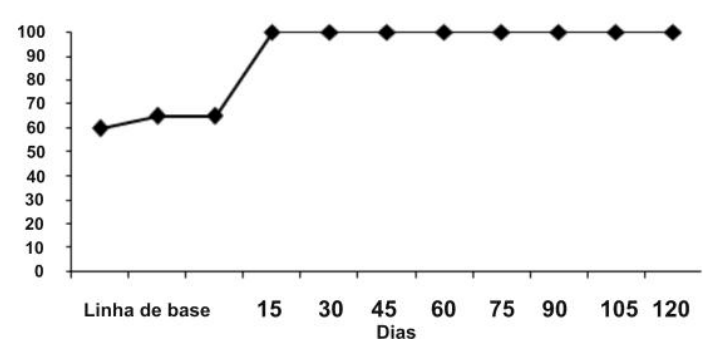

Figura 1. Porcentagem de emissões corretas das habilidades que não foram alvo de intervenções, avaliadas quinzenalmente ao longo do programa de ensino.

Os dados das habilidades que não foram alvo de intervenção não apresentaram mudança significativa ao longo das sessões, como mostra Figura 1. As habilidades que, na linha de base, apresentaram altas porcentagens de emissão correta, assim se mantiveram no decorrer da aplicação do programa de ensino (caso das habilidades "localizar fontes sonoras", "explorar o ambiente com as mãos" e "manipular objetos que entrem no campo visual"). Já as habilidades com por- centagens de emissão correta inferiores a 70\% ("explorar diferentes texturas", "perceber sons de diferentes intensidades" e "identificar objetos por meio de contato físico") mantiveram esses percentuais durante a fase de intervenção, com desempenhos irregulares que não configuraram alteração significativa na emissão da conduta. A única exceção ocorreu com a habilidade "perceber diferentes estímulos visuais", que na linha de base foi emitida corretamente em $68 \%$ das 
ocasiões avaliadas, e que passou a ser emitida corretamente em $100 \%$ das avaliações no decorrer das sessões de intervenção, embora não tenha sido alvo de intervenções específicas.

Na Figura 2, que apresenta os dados relativos às habilidades que foram alvo do programa de ensino, pode-se observar o aumento da porcentagem de emissões corretas das três condutas ensinadas a partir do momento em que foram iniciadas as intervenções. A linha tracejada indica o início da implementação do programa de ensino para cada habilidade. Inicialmen- te, foram ensinadas as habilidades "procurar objetos" e "contato visual". Após a apresentação de 100\% de acerto da conduta "procurar objetos" foi iniciado o procedimento de ensino da conduta "imitação motora”. É possível observar o aumento da porcentagem de emissões corretas dessa conduta após a segunda revisão quinzenal desde o início da intervenção, aumento que se manteve ao longo do programa de ensino. A porcentagem de acertos da conduta "contato visual" foi variável ao longo das avaliações, mas apresentou clara melhora no decorrer do programa.

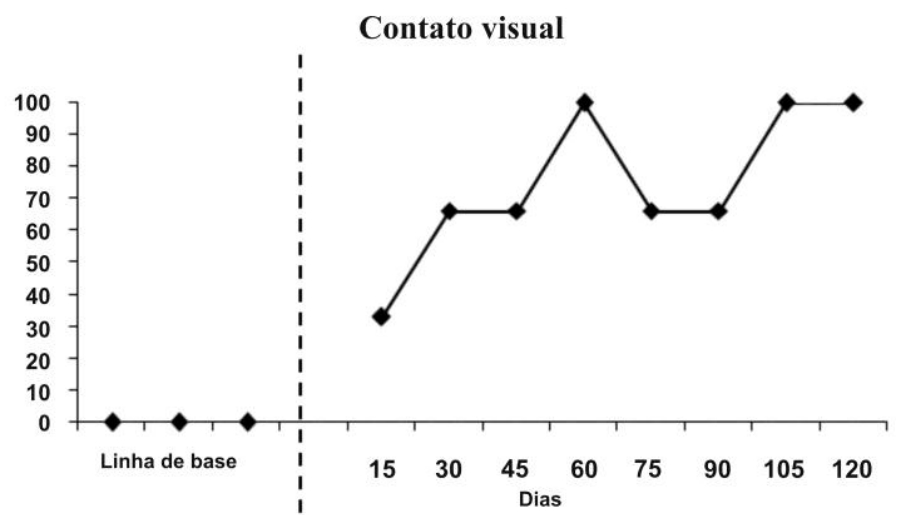

Procurar objetos

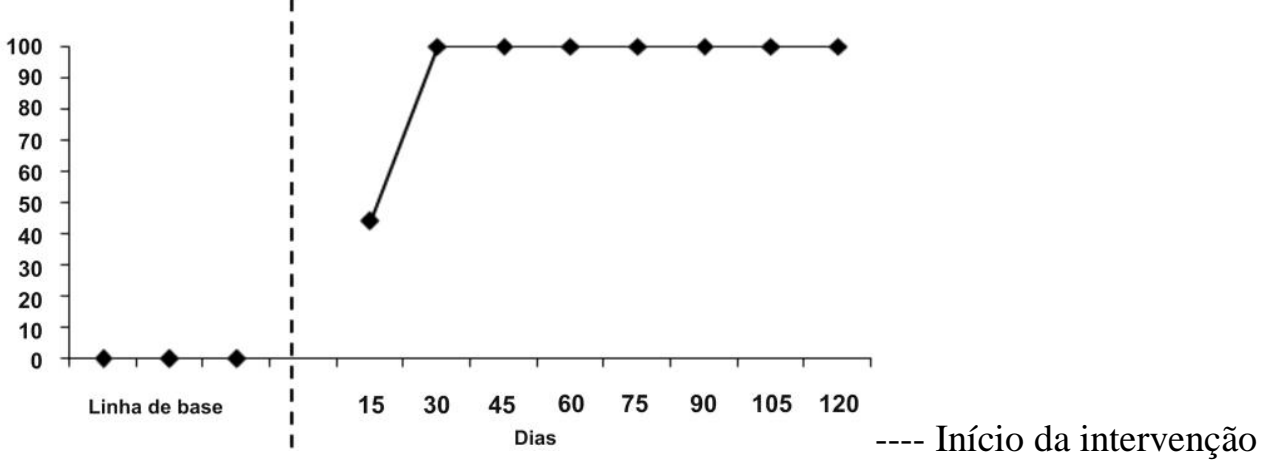

Imitação motora

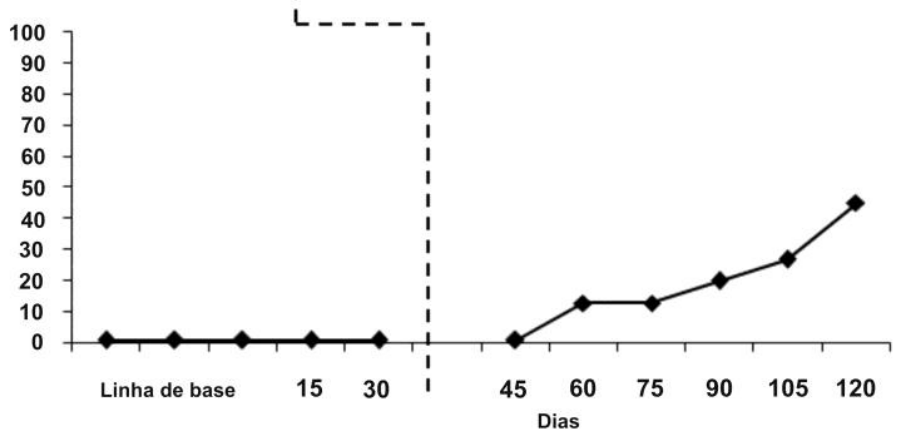

Figura 2. Porcentagem de emissões corretas das habilidades que foram alvo de intervenções, avaliadas quinzenalmente ao longo do programa de ensino. 
Estes dados sugerem que o plano de intervenção realizado para ensino das habilidades "procurar objetos", "contato visual" e "imitação motora" produziu modificações no repertório comportamental da participante. As demais habilidades que foram avaliadas quinzenalmente e não foram inseridas no plano de intervenção, de modo geral, não apresentaram modificações significativas ao longo do trabalho.

\section{DISCUSSÃO}

O objetivo do trabalho aqui apresentado foi verificar as eventuais mudanças ocorridas no repertório de uma criança com deficiência, institucionalizada e em condição de abandono, quando exposta a um procedimento focado no ensino de habilidades básicas. A participante deste estudo foi institucionalizada aos três anos de idade e aos sete (quando do início desta pesquisa), apresentava um repertório bastante limitado no que se refere às condutas iniciais do desenvolvimento infantil, como pode ser verificado pelos dados da avaliação de habilidades básicas, aplicada antes do início do programa de ensino (linha de base). Ao chegar à instituição, constava em seu prontuário que se tratava de uma criança que apresentava atrasos significativos no desenvolvimento, ainda que não houvesse um diagnóstico identificável para tais atrasos. Crianças nessas condições, conforme aponta a literatura, necessitam de intervenções precoces para o desenvolvimento de seu potencial.

Rodrigues e Santos (2004) relatam a importância do acompanhamento especializado precoce para bebês de alto risco, com intervenções específicas para suas necessidades. De acordo com a literatura, as crianças que recebem intervenções em seus primeiros anos de vida têm maior probabilidade de desenvolver plenamente seu potencial. Por outro lado, a criança que vive em um ambiente pouco propício à aprendizagem e que não tem a oportunidade de passar por procedimentos específicos que a auxiliem no desenvolvimento de habilidades básicas, por exemplo, apresentará déficits na aprendizagem de comportamentos mais complexos (Windholz, 1988). A literatura da análise aplicada do comportamento é farta em dados que mostram que a partir da manipulação de contingências pode-se estabelecer ou ensinar comportamentos, alterar padrões, assim como reduzir, enfraquecer ou eliminar condutas do repertório dos indivíduos (de Souza, 2001). Intervenções dessa natureza para pessoas que apresentam atrasos no desenvolvimento ou deficiências têm sido testadas em pesquisas (por exemplo, Bagaiolo \& Guilhardi, 2002; Hersen \& Bellack, 1976) e sistematizadas em currículos funcionais (por exemplo, Bereohff, Leppos \& Freire, 1994; Johnson-Martin e cols., 1997; Sant'anna e cols., 1996; Windholz, 1988). Nesses trabalhos, porém, sugere-se que a eficácia dos procedimentos de ensino está sempre relacionada à sua frequência de aplicação: no mínimo três vezes ao dia em todos os dias da semana.

Os resultados apresentados neste trabalho, no entanto, mostraram que o programa de ensino empregado na intervenção mostrou-se eficaz ainda que aplicado em uma sessão por dia, três vezes por semana. Mesmo em um ambiente onde não havia qualquer arranjo específico que favorecesse a aprendizagem dos residentes, a participante apresentou um aumento da frequência de emissão das condutas ensinadas a partir dos procedimentos de ensino adotados. Provavelmente, com uma maior frequência de sessões diárias e um número maior de sessões por semana, a frequência das habilidades ensinadas seria maior no mesmo período de intervenção (quatro meses), mas pode-se verificar que, mesmo em condições longe das ideais, a intervenção foi bem sucedida.

Optou-se por iniciar a intervenção pelo ensino das habilidades "procurar objetos" e "contato visual" por serem condutas cujos pré-requisitos já estavam presentes no repertório da participante. Um mês após o início da intervenção, a primeira habilidade foi considerada aprendida, uma vez que a criança apresentou essa conduta todas as vezes que foi solicitada, durante três sessões consecutivas. Com o ensino da habilidade, "contato visual", porém, o mesmo não ocorreu. Apesar do aumento significativo da frequência de emissão dessa conduta ao longo das avaliações quinzenais, a emissão desse comportamento nas avaliações não foi regular, o que indica que, para essa conduta específica, provavelmente seria necessário um número maior de intervenções. Levando-se em conta as características comportamentais da participante e as hipóteses diagnósticas da avaliação médica (Transtorno Invasivo do Desenvolvimento), é possível que a dificuldade na aprendizagem do contato visual tenha relação com aspectos inerentes ao quadro clínico, conforme dados da literatura médica (American Psychiatric Association, 2005). Pesquisas com crianças com transtorno invasivo do desenvolvimento (Hutt \& Ounsted, 1966, citados por Holmes, 2001) demonstraram que estas crianças, se comparadas a pares de mesma faixa etária com desenvolvimento típico, apresentam preferência significativa por olhar estímulos ambientais não humanos. Foi observado que a participante deste estudo também mostrava preferência em olhar em direção aos objetos ao invés de realizar contato 
visual com as pessoas ao seu redor, o que reforça a ideia da necessidade de intervenções mais frequentes para o ensino dessa habilidade.

Provavelmente, a variabilidade na frequência de emissão de contato visual interferiu na aprendizagem da habilidade "imitação motora", para a qual o comportamento de olhar para o modelo é um pré-requisito. Apesar disso, foi possível observar um aumento consistente na frequência dessa conduta, embora mais lento do que aquele observado na habilidade "procurar objetos".

Embora não tenha sido observada uma diferença significativa entre os dados de linha de base e os das avaliações quinzenais finais das habilidades que não passaram por procedimentos específicos de ensino, observou-se um aumento na frequência de emissão correta de quatro destas habilidades ("localizar fontes sonoras", "explorar o ambientes com as mãos", manipular objetos que entrem no campo visual" e "perceber diferentes estímulos visuais"), habilidades que, na linha de base, apresentaram frequências de emissão correta superiores a $60 \%$. Este aumento ocorreu no período em que se iniciaram as intervenções com as habilidades "procurar objetos" e "contato visual".

Considerando que pelo menos três dessas habilidades que não foram ensinadas explicitamente tinham, de certa forma, relação com as habilidades que foram alvo das intervenções específicas, parece compreensível o aumento registrado em suas frequências a partir da primeira avaliação quinzenal. Por exemplo, "explorar o ambiente com as mãos" era uma habilidade envolvida no ensino de "procurar objetos". Nesse caso, os dados sugerem que a habilidade "explorar o ambiente com as mãos" pode ter sido ensinada de forma incidental.

Almeida (1993), ao relatar uma pesquisa sobre variações do ensino incidental, dá exemplos deste procedimento para desenvolvimento da linguagem oral em indivíduos com deficiência mental, durante o horário das refeições. O ensino incidental pode ser propiciado pelo professor ou pesquisador que está em contato com o aprendiz e consiste em, a partir de atividades cotidianas, promover a aprendizagem de comportamentos ausentes ou fracamente instalados no repertório do participante (Warren \& Kaiser, 1986). No caso de três das habilidades não diretamente ensinadas, mas que apresentaram aumento na frequência de emissões corretas, parece que condutas que foram fortalecidas durante o ensino de "procurar objetos" e "contato visual" estavam diretamente relacionadas às habilidades "explorar o ambientes com as mãos", manipular objetos que entrem no campo visual" e "perceber diferentes estímulos visuais". Novamente, porém, é importante ressaltar que as diferenças entre os dados de linha de base e os dados das avaliações quinzenais dessas últimas condutas não são significativas a ponto de se poder afirmar com segurança que ocorreu o ensino incidental.

Outro fator importante a ser considerado nessa pesquisa é a importância de um ambiente favorável à generalização das habilidades básicas que foram ensinadas. Durante a implementação do programa de ensino, verificou-se que quando a criança foi submetida a um arranjo planejado de contingências reforçadoras, apresentou um aumento significativo na frequência de emissão correta das habilidades ensinadas. Estes resultados demonstram que a criança tinha possibilidades de aprender e que não apresentava tais condutas anteriormente por falta de um arranjo de contingências que favorecessem a sua aquisição. Na sequência do trabalho, seria necessário que as habilidades aprendidas nas sessões de intervenção fossem fortalecidas quando apresentadas pela participante em situações cotidianas de sua vida. Dessa forma, seria possível fazer a transição dos reforçadores arranjados para reforçadores naturais para a manutenção dessas condutas, criando-se contingências que fortalecessem o comportamento aprendido todas as vezes em que ele fosse emitido, possibilitando, então, a generalização dessas habilidades para outros ambientes e situações.

No entanto, para que isso fosse possível seriam necessárias modificações no ambiente no qual a criança estava inserida. A instituição em que ela residia não apresentava condições para isso. $\mathrm{O}$ arranjo de contingências de ensino requer que aqueles que são responsáveis pelo ensino de uma conduta sejam capazes de analisar a tarefa a ser ensinada, avaliar o repertório de entrada de quem vai aprender, programar e administrar consequências eficazes para o desempenho do aprendiz e formular um programa de ensino que integre todos esses elementos (Matos, 1992). Como na maioria das instituições residenciais do país, os atendentes da instituição onde foi realizado o presente estudo não tinham uma formação que lhes permitisse desempenhar essas atividades.

Tais questões apontam para a necessidade de se discutir o papel dos profissionais que trabalham diretamente com pessoas com deficiência que estão em situação de institucionalização. De acordo com a descrição do IBGE (2006) deste modelo de instituição, os profissionais que trabalham como cuidadores em instituições residenciais devem ter formação de auxiliares de enfermagem ou de enfermeiros. Sabe-se que tais 
formações não preparam os profissionais para que eles possam conduzir procedimentos de ensino específicos para pessoas que tenham qualquer tipo de deficiência, o que faz com que seja ainda mais difícil que pessoas com limitações em seu desenvolvimento possam aprender condutas funcionais que demandem ensino direto. Considerando que algumas experiências com o treinamento de atendentes de instituições residenciais surtiram resultados muito positivos (Grossi, 1996; Prada, 2007), parece necessário, então, que sejam desenvolvidos trabalhos que sistematizem formas de se capacitar profissionais que trabalham como cuidadores em instituições residenciais a promover situações de ensino para os residentes, sobretudo para aqueles com maiores dificuldades de aprendizagem, como foi o caso da participante deste estudo. Pesquisas futuras nesses ambientes institucionais também deveriam investigar, na rotina dos cuidadores, momentos que poderiam servir para o ensino de habilidades em defasagem ou ausentes no repertório dos residentes, assim como formas de tornar os ambientes institucionais mais propícios à aprendizagem, possibilitando a aquisição de novas habilidades e o pleno desenvolvimento de seu potencial.

\section{REFERÊNCIAS}

Almeida, M. (1993). As variações de ensino incidental e o desenvolvimento da linguagem oral em indivíduos portadores de deficiência mental. Temas em Psicologia, 1(2), 117-126.

American Psychiatric Association. (2005). Manual diagnóstico e estatístico de transtornos mentais - DSM - IV TR. Porto Alegre: Artes Médicas Sul.

Araujo, P. M., \& Ferreira, P. R. S. (2008). Ensinando subtração para pessoas com deficiência mental com base em relações de equivalência de estímulos. Psicologia: Teoria e Pesquisa, 24, 313-322.

Bagaiolo, L., \& Guilhardi, C. (2002). Autismo e preocupações educacionais: Um estudo de caso a partir de uma perspectiva comportamental compromissada com a análise experimental do comportamento. Em H. J. Guilhardi, M. B. B. P. Madi, P. P. Queiroz \& M. C. Scoz (Orgs.), Sobre Comportamento e Cognição: Vol. 9. Contribuições para a construção da teoria do comportamento (pp. 67-82). São Paulo: Esetec.

Bereohff, A. M. P., Leppos, A. S. S., \& Freire, L. H. V. (1994). Considerações técnicas sobre o atendimento psicopedagógico do educando portados de condutas típicas da síndrome do autismo e de psicoses infanto-juvenis. Brasília: ASTECA.

Braga-Kenyon, P., Kenyon, S., \& Miguel, C. F. (2002). Análise do comportamento aplicada: Um modelo para educação especial. Em W. Camargos (Org.), Transtornos invasivos do desenvolvimento (pp. 148-154). Brasília: CORDE.

Carvalho, C. (2006). Um olhar sobre o abrigamento: A importância das histórias infantis em contexto de abrigo. Dissertação de mestrado não-publicada, Universidade de Uberlândia.
Carvalho Neto, M. B. (2002). Análise do comportamento: Behaviorismo radical, análise experimental do comportamento e análise aplicada do comportamento. Interação em Psicologia, 6, 13-18.

Costa, A. (2005). Um estudo sobre o impacto das (des)conexões entre o ambiente escolar $e$ o ambiente institucional na vida de crianças e adolescentes abrigados. Dissertação de mestrado não-publicada, Fundação Universidade Federal do Rio Grande.

Cozby, P. (2003). Métodos de pesquisa em ciências do comportamento. São Paulo: Atlas.

De Souza, D. G. (2001). O que é contingência. Em R. A. Banaco (Org.), Sobre comportamento e cognição: Vol. 1. Aspectos teóricos, metodológicos e de formação em análise do comportamento e terapia cognitivista (pp. 82-87). São Paulo: Esetec.

Grossi, R. (1996). Capacitação de atendentes em situação natural: Um programa de ensino de tarefas de cuidados pessoais para criança portadora de deficiência mental. Dissertação de mestrado não-publicada, Universidade Federal de São Carlos.

Hersen, M., \& Bellack, A. S. (1976). A multiple-baseline analysis of social-skills training in chronic schizophrenics. Journal of Applied Behavior Analysis, 9, 239-245.

Holmes, D. S. (2001). Psicologia dos transtornos mentais. São Paulo: Artmed.

Instituto Brasileiro de Geografia e Estatística. (2007). As entidades de assistência social privadas sem fins lucrativos no Brasil. Retirado em 28 de maio de 2008 de http://www.ibge.gov.br /home/estatisitica/economia/peas/2006/assistencia_social_priva da2006.pdf

Johnson-Martin, N. M. (1997). Currículo Carolina: Evaluación y ejercicios para bebés y niños pequeños com necesidades especiales. Madrid: TEA.

Matos, M. A. (1997). Com o que o behaviorismo radical trabalha. Em R. A. Banaco (Org.), Sobre comportamento e cognição: Vol. 1. Aspectos teóricos, metodológicos e de formação em análise do comportamento e terapia cognitivista (pp. 45-53). São Paulo: Esetec.

Matos, M. A. (1992). Análise de contingências no aprender e no ensinar. Em E. S. Alencar (Org.), Novas contribuições da psicologia aos processos de ensino e aprendizagem (pp. 141-165). São Paulo: Cortez.

Micheletto, N. (1997). Bases filosóficas do behaviorismo radical. Em R. A. Banaco (Org.), Sobre comportamento e cognição: Vol. 1. Aspectos teóricos, metodológicos e de formação em análise do comportamento e terapia cognitivista (pp. 29-44) São Paulo: Esetec.

Orionte, I. (2004). Abandono e institucionalização de crianças: Significados e sentidos. Dissertação de mestrado não-publicada, Pontifícia Universidade Católica de Goiás, Goiânia.

Paula, A. R. (2008). Asilamento de pessoas com deficiência: Institucionalização da incapacidade social. São Paulo: MEMMON

Prada, C. G. (2007). Avaliação de um programa de práticas educativas para monitoras de um abrigo infantil. Dissertação de mestrado não-publicada, Universidade Federal de São Carlos.

Rodrigues, O. M. P. R., \& Santos, A. P. A. (2004). Análise qualitativa de propostas de estimulação precoce. Em O. M. P. R. Rodrigues, T. G. M. Valle, A. C. M. Almeida-Verdu, J. LopesJunior \& M. R. Cavalcante, Psicologia do desenvolvimento e aprendizagem: Investigações e análises (pp. 3-18). São Paulo: Rima. 
Salina, A. (2007). O abrigo como fator de risco e proteção: Indicadores e avaliação institucional. Dissertação de mestrado não-publicada, Universidade Federal de São Carlos.

Sant'Anna, F. M., Enricone, D., André, L., \& Turra, C. M. (1996). Planejamento de ensino e avaliação. Porto Alegre: Sagra/DC Luzzatto.

Santos, M. L., Almeida, M. A., \& Bzuneck, J. A. (1992). A atuação de alunas de magistério em treinamento de AVD numa APAE: Uma análise experimental. Revista Brasileira de Educação Especial, 1, 39-51.

Silva, F. C. T. (1999). Procedimentos didáticos "especiais" no ensino do deficiente mental: Um caminho de interlocução. Revista Brasileira de Educação Especial, 5, 27-39.

Spangler, P. F., \& Marshall, A. M. (1983). The unit play manager as facilitator of purposeful activies among institucionalized profoundly and severely retarded boys. Journal of Applied Behavior Analysis, 16, 345-349.
Todorov, J. C. (1982). Behaviorismo e análise experimental do comportamento. Cadernos de Análise do Comportamento, 3, $10-23$.

Warren, S. F., \& Kaiser, A. P. (1986). Incidental linguagem teaching: A critical review. Journal of Speech and Hearing Disorders, 51, 291-299.

Windholz, M. H. (1988). Passo a passo, seu caminho: Guia curricular para ensino de habilidades básicas. São Paulo: Edicon.

Windholz, M. H., \& Meyer, S. B. (2000). Crianças com problemas de desenvolvimento. Em E. F. M. Silvares (Org.), Estudos de caso em psicologia clínica comportamental infantil: Vol. 1 (pp. 223-258). São Paulo: Papirus.

\section{Sobre as autoras:}

Recebido: $14 / 08 / 2009$ Última revisão: $13 / 06 / 2010$ Aceite final: $14 / 07 / 2010$

Iasmin Zanchi Boueri: Psicóloga, doutoranda em Educação Especial pela Universidade Federal de São Carlos.

Andréia Schmidt: Psicóloga, Doutora em Psicologia Experimental pela USP, professora da Universidade de São Paulo - Faculdade de Filosofia, Ciências e Letras de Ribeirão Preto.

Endereço para correspondência: Andréia Schmidt - Av. Bandeirantes, 3900 - Bairro Monte Alegre. 14040-901 Ribeirão Preto/SP -. Endereço eletrônico: aschmidt@ffclrp.usp.br; iasmin1984@yahoo.com.br. 